\title{
Outdoor Thermal Comfort Improvement of Campus Public Space
}

\author{
Damrongsak Rinchumphu ${ }^{1,2, *}$, Non Phichetkunbodee ${ }^{1,2}$, Nakarin Pomsurin ${ }^{1,2}$, \\ Chawanat Sundaranaga $^{2}$, Sarote Tepweerakun ${ }^{2}$, Chatchawan Chaichana ${ }^{3}$ \\ ${ }^{1}$ Department of Civil Engineering, Faculty of Engineering, Chiang Mai University, Chiang Mai, Thailand \\ ${ }^{2}$ Civil Innovation and City Engineering Laboratory, Chiang Mai, Thailand \\ ${ }^{3}$ Department of Mechanical Engineering, Faculty of Engineering, Chiang Mai University, Chiang Mai, Thailand \\ Received 20 September 2020; received in revised form 31 January 2021; accepted 01 February 2021 \\ DOI: https://doi.org/10.46604/aiti.2021.6453
}

\begin{abstract}
This study focuses on the design of a campus public space, located within the Faculty of Engineering, Chiang Mai University, Thailand. This area faces extreme temperatures, creating uncomfortable outdoor thermal conditions and hindering activities that are expected to support the learning and social cohesion needs of students. To create the best conditions in this space, three design alternatives such as adding a pond, large trees, or shrubs were considered, and the Physiologically Equivalent Temperature (PET) was used to calculate the outdoor thermal comfort index for each alternative. The alternatives were then compared to the base case. The PET can be calculated using the ENVI-met simulation software following the appropriate field data collection and calibration process. The results showed that adding large trees in the south-west area is the best design alternative. The PET for this alternative was $3.17 \%$ lower than the base case. In addition, this design workflow is an effective working model for further outdoor public space designs to meet the constraints of effective sustainable development in any tropical campus area.
\end{abstract}

Keywords: outdoor public space, thermal comfort, physical equivalent temperature, design alternative

\section{Introduction}

The development of a university's outdoor activity area is often in response to the learning and social needs of students, and its building is an important policy of Chiang Mai University, as it has a focus on creating an environment that is attractive and suitable to be used appropriately [1]. Outdoor public space development should be based on indicators that reflect the conditions for the actual use. Weather conditions that are not too hot or too cold will have a positive effect on the students who use the outdoor public space for studying as the conditions outside the building are comfortable [2-4]. Suitable outdoor thermal conditions for comfort are related to air temperature, relative humidity and wind speed that make the human body feel comfortable [5].

From several research studies, there are a number of outdoor thermal comfort indicators. A commonly used indicator is the Physiologically Equivalent Temperature (PET) [6-8]. The PET is based on modeling the heat balance of the human body. The numerical values are based on the evaporation of moisture related to the heat and air mass, and it is the heat that can maintain the heat balance in humans. PET is also an indicator that can explain the thermal exchange between the body and the environment, and it is used for outdoor comfort analysis. The measured variables are air temperature, relative humidity, wind speed, average heat radiation value and the variables of the human natural state that tries to present them, so they are comparable to human feelings [6, 9].

* Corresponding author. E-mail address: damrongsak.r@ cmu.ac.th

Tel.: +66-95-9959519; Fax: +66-53-892376 
To develop an outdoor public space that it is more sustainable, this study focuses on outdoor thermal comfort improvement, as represented by the PET around the area within the boundary of the Lan Witsawa Ruamjai, which is the space for outdoor activities on the campus. The result is expected to identify the best alternative design for outdoor public space. The workflow from this study could be used as a framework for improving other campus outdoor public spaces to meet smart campus policy of universities in the future.

The paper is structured in five sections: (1) introduction, (2) Physiologically Equivalent Temperature (PET), (3) research methodology, (4) results and discussion and (5) conclusions.

\section{Physiologically Equivalent Temperature (PET)}

There are several indices used to measure the outdoor thermal comfort level [7, 10], for example, Predicted Mean Vote (PMV), Effective Temperature (ET), Perceived Temperature (PT), Physiological Equivalent Temperature (PET) and Universal Thermal Climate Index (UTCI). According to the research conducted by Johansson [11] and Klaylee [12], PET is the most suitable indicator for assessing the outdoor thermal comfort. PET can be calculated by a computer program, which represents a realistic state from an airflow simulation program. The most effective simulation software is ENVI-met V 4.4 [9]. PET is affected by four environmental factors as follows:

\subsection{Air temperature}

Air Temperature is a fundamental factor in climate studies, which always changes over time and varies by season. The comfortable temperature for humans outside a building in Greece, according to a study by Matzarakis et al. [13], was found to be between $18-23{ }^{\circ} \mathrm{C}$, with relative humidity and air velocity at optimal conditions. However, Srivanit \& Auttarat [14] conducted a study in Chiang Mai Province, and concluded that the average outdoor comfortable condition was 23.0 - 31.0 ${ }^{\circ} \mathrm{C}$, which is related to the local conditions of the area in this study.

\subsection{Relative humidity}

Relative Humidity is the ratio of the amount of water vapor in the air at that time compared to the amount of water vapor that the air can accept. The relative humidity in Thailand, which is located in the tropical climate zone, during the summer is up to $90 \%$, while in the winter it may drop below $40 \%$, which is approximately $60-70 \%$ on average. However, if the relative humidity level is too high, it can make human sweat more result in difficult evaporation, and causes them to feel hot and uncomfortable. While a too low relative humidity will irritate the skin [12].

\subsection{Air velocity}

Air velocity is a factor that affects the heat transfer of the body. An uncomfortable situation may be caused by convection when the wind speed increases, and humans will feel colder than the actual temperature. Due to the higher cooling rate from the body surface, humans feel $0.4{ }^{\circ} \mathrm{C}$ cooler than the actual air temperature when the wind speed increases by $1 \mathrm{~km} / \mathrm{hr}$. Humans may feel especially cold if the wind speed is too high and the temperature is too low. On the other hand, if the weather is hot and the air velocity is low, the air will not take the heat out of the body, and this causes humans to feel hot and uncomfortable. The wind speed will vary depending on the physical environment and location [9]. It was found that humans feel comfortable with an air velocity of $0.25-0.50 \mathrm{~m} / \mathrm{s}$ [15].

\subsection{Solar radiation}

Solar radiation is the electromagnetic waves emitted from the sun. People often call it sunlight, but the electromagnetic waves are not the only light as there are also other rays [16]. However, the radiation from the sun varies by specific place. 
International studies often use a specific city or country to measure the solar radiation when calculating the outdoor thermal comfort. A survey was conducted, and it showed that the average solar radiation value for Thailand was $219.9 \mathrm{~W} / \mathrm{m}^{2}$ [17].

Furthermore, this study has found 4 factors that are not direct design elements but are consequences of the design and selection of open space. For example, increasing the number of trees or buildings can reduce the temperature of the area. In addition, from the literature review [18-19], there are experiments on modifying the area by changing the surface and green components, such as replacing the land surface with a waterscape. This will increase the water surface area, which affects the temperature and humidity of the surrounding area [19]. Increasing the number of trees of various sizes can also decrease the temperature. A tree of any shape and size will affect the shading, wind speed, and solar radiation, resulting in a lower PET value and increasing outdoor thermal comfort in the area, especially in tropical areas such as Chiang Mai, Thailand [20]. These factors can be used when planning and creating outdoor public space design alternatives as well as for determining PET, as per the purpose of this research [21].

\section{Research Methodology}

The research methodology includes two parts: the first part is selecting a study area and defining the base case and setting the alternative cases model. The second part is the process of the model simulation and analysis.

\subsection{Selecting study area and models setting}

The study area is named Lan Witsawa Ruamjai, an open public space, located in the Faculty of Engineering, Chiang Mai University, Chiang Mai, Thailand. It is a space that students can use for relaxation or activities in the university. This research defines the boundary of the study area using aerial images from Google Earth at the latitude and longitude of 18.7942153, 98.9512263, respectively (Fig. 1).

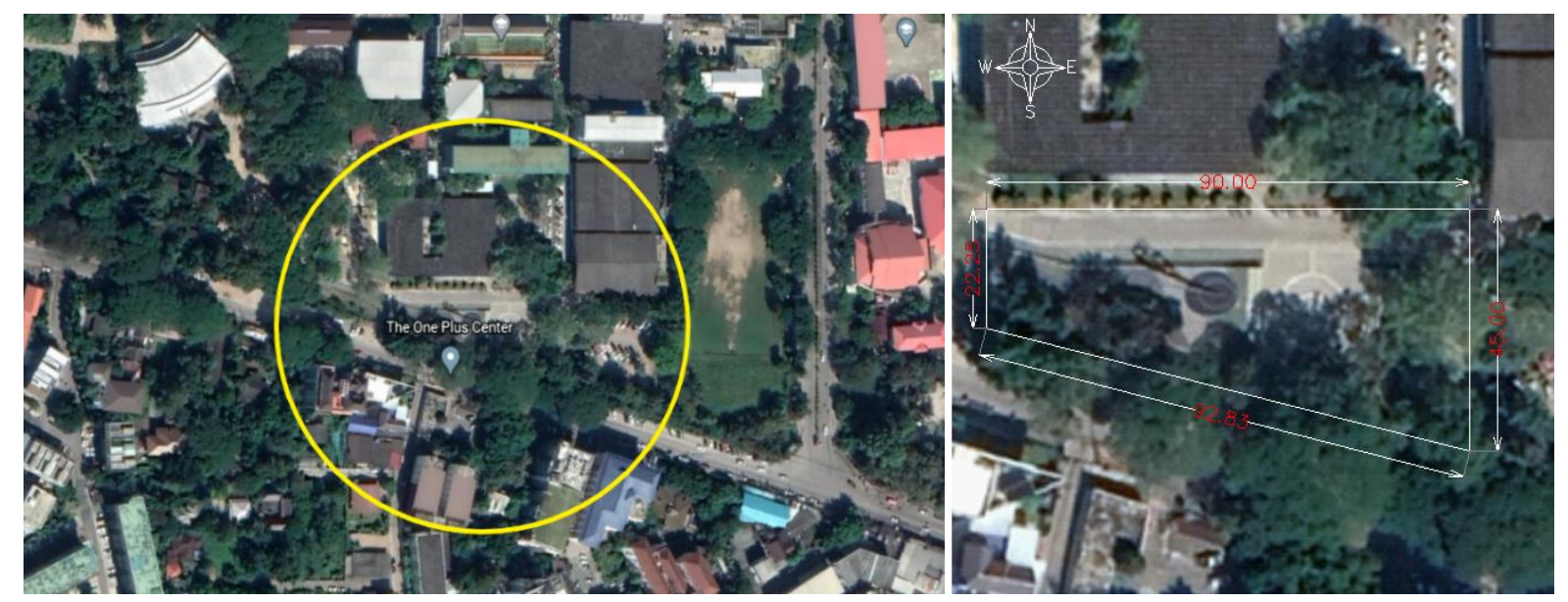

Fig. 1 Aerial view of Lan Witsawa Ruamjai, Chiang Mai University
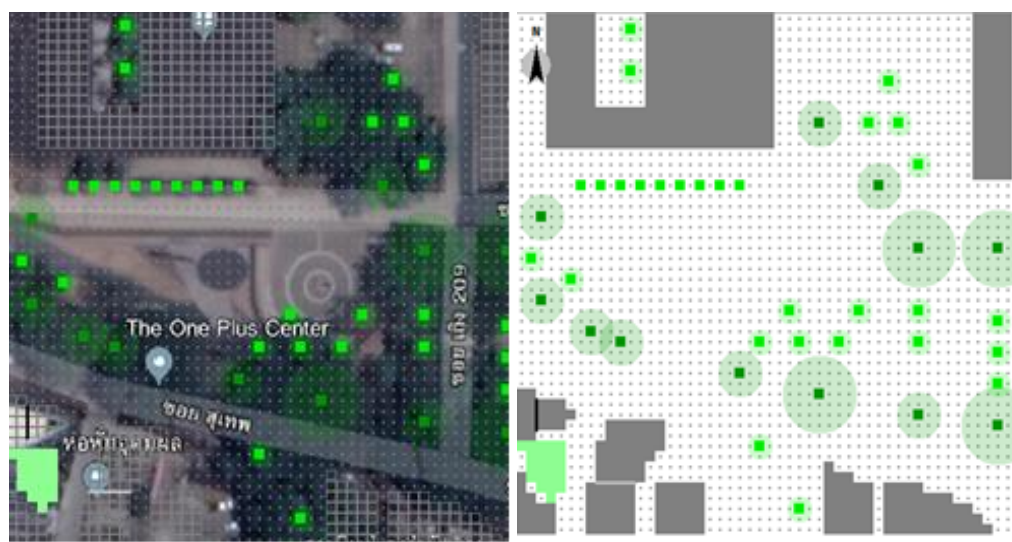

Fig. 2 2D model of study area presented in ENVI-met version 4.4 
The total area of the space is $3,023.0 \mathrm{~m}^{2}$, including $1,114.4 \mathrm{~m}^{2}$ of hardscape and 1,908.6 $\mathrm{m}^{2}$ of softscape, which consists of shrubs and trees. In a radius of $50 \mathrm{~m}$, the area is surrounded by buildings with 1- 6 floors, asphalt concrete road, ditch, green spaces and big trees as shown in Fig. 2.

According to the design guideline in the TREES-NC standard in Section 2: site and landscape, the PET value depends on the land surface type, number, and location of trees and shrubs [22]. After determining the existing physical characteristics of the base case, the design alternatives will be developed following the TREES - NC standard with three options of adding a pond as a water surface area and adding large trees and shrubs, specifically in the south-west of the study area. The details of the three alternative designs are shown in Table 1 and presented as follows:

Alternative 1: Replacing the surface of the space with a $2 \mathrm{~m}$ deep pond. The pond would be semi-natural, with a small water treatment system. The pond would increase the relative humidity and also absorbs solar radiation to reduce the PET.

Alternative 2: Plant cork trees, shading, broad and dense foliage over an area of $10 \mathrm{~m}$ with perennial trees in the south-west of the study area. These trees will provide shade during daytime, especially in the afternoon when the temperature is at its peak. The large trees will also be able to block radiation from the sun.

Alternative 3: Medium sized shrubs planted around the study area in the south-west. It may add a little shade to the study area and can provide some degree of protection against solar radiation.

Table 1 Details of design alternatives

\begin{tabular}{|c|c|c|}
\hline Design Alternative & Design Type & Details \\
\hline Base case & Concrete pavement & Light gray color \\
\hline Alternative 1 & Pond & 2 m depth \\
\hline Alternative 2 & Large trees & $\begin{array}{c}\text { Diameter of shading area }>10 \mathrm{~m} \\
\text { Two large trees of native plant (cork tree) } \\
\text { South }- \text { West* }\end{array}$ \\
\hline Alternative 3 & Shrubs & $\begin{array}{c}\text { Diameter of shading area }<5 \mathrm{~m} \\
\text { Medium sized shrubs (banyan tree) } \\
\text { South }- \text { West* }\end{array}$ \\
\hline
\end{tabular}

* According to the Srivanit \& Hokao [20] explained that Chiang Mai, Thailand is located at longitude $18.7942153^{\circ} \mathrm{N}$, therefore the Sun direction will lay on the south side of the area for most of the year, and the Sun will raise the air temperature during the afternoon time on the west direction for the whole year, then the most efficient thermal protection concerned must be focused on the south-west direction for this study area.

\subsection{Model simulation processes}

The measured meteorological data includes the air temperature, relative humidity, wind speed and solar radiation, as these are the main factors that are directly related to the daily climate. This research was to determine the average daily temperature over the five years 2015-2019 to identify the days with the highest average temperature during the year. The data is from a weather monitoring station of the Meteorological Department, the Northern Meteorological Center. The monitoring station, located in Suthep Subdistrict, Mueang Chiang Mai District, Chiang Mai, is the closest weather monitoring station to the study area, approximately 2.35 kilometers from the site. The highest average five-year (2015-2019) temperature was on April 13, this day will be used in this study.

The field data was obtained from a LUTRON WBGT-2010SD instrument to measure the air temperature, relative humidity, mean radiant temperature, and were calculated using a diameter globe thermometer at $75 \mathrm{~mm}$. The wind velocity was measured using a hot-wire anemometer that was recorded in the TESTO 435-2 data logger and used to calculate the mean radiant temperature $\left(\mathrm{T}_{\mathrm{mrt}}\right)$ according to Eq. (1). 


$$
T_{m r t}=\left[\left(T_{g}+273.15\right)^{4}+\frac{1.335 \times 10^{8} V_{a}^{0.71}}{\varepsilon D^{0.4}}\left(T_{g}-T_{a}\right)\right]^{\frac{1}{4}}
$$

where $\mathrm{T}_{\mathrm{g}}$ is the globe temperature $\left({ }^{\circ} \mathrm{C}\right), \mathrm{V}_{\mathrm{a}}$ is the wind speed $(\mathrm{m} / \mathrm{s}), \mathrm{T}_{\mathrm{a}}$ is the air temperature $\left({ }^{\circ} \mathrm{C}\right), \mathrm{D}$ is the globe thermometer diameter $(\mathrm{m})$ and $\varepsilon$ is the globe emissivity $(\varepsilon=0.95)$. The air temperature, relative humidity and wind speed were collected from 07:00-18:00. on April 13 ${ }^{\text {th }}, 2020$, by the LUTRON WBGT-2010SD for the data calibration process.

After collecting the weather data, the model calibration process was started by comparing the $\mathrm{T}_{\text {mrt }}$ between the computer simulation and the field results. The ENVI-met simulation program was used for calibration, and the results of the field calibration and the five-year average dataset of the Meteorological Department were compared. By comparing the similarity of the data set with the root mean square error (RMSE) and Willmott's index of agreement (d), the RMSE and d result must be within the acceptable range of $0.66-7.98$ and $0.53-0.95$, respectively [23]. If they are not in the range, a trial-and-error process must be applied until the RMSE and d values are within the acceptable range. After three rounds of calibration, RMSE $=1.94$ and $d=0.75$ were within the acceptable range. The four models in this study, base case and three alternative cases, are presented in Fig. 3. The PET simulation results of each model will be presented in the next section.

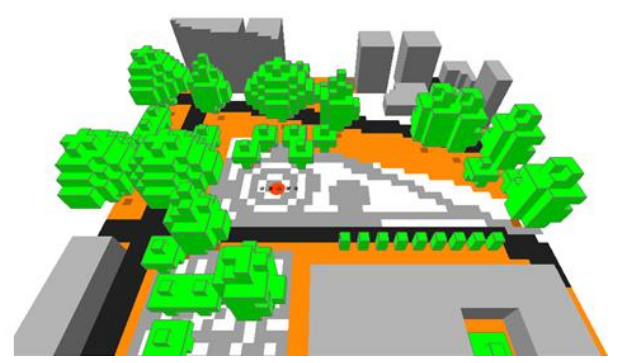

(a) Base case

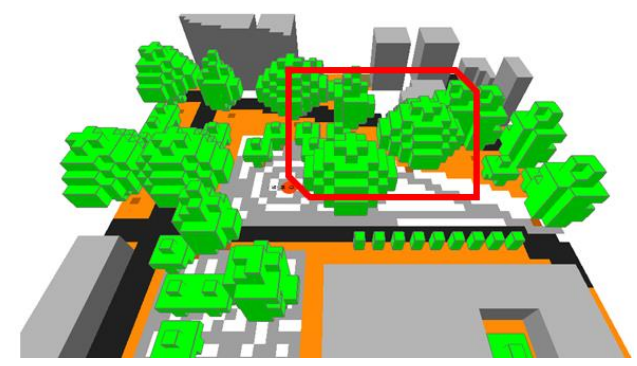

(c) Alternative 2

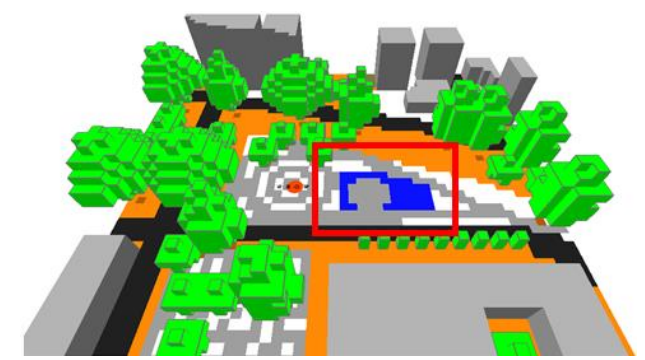

(b) Alternative 1

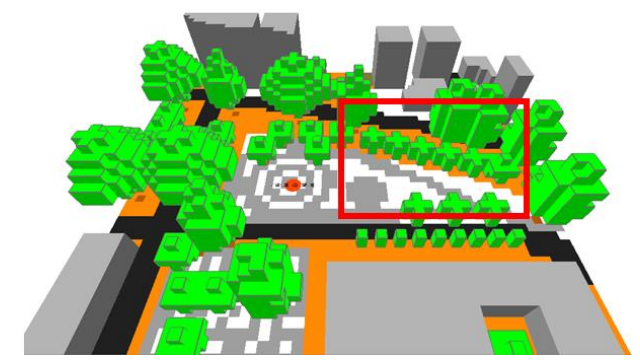

(d) Alternative 3

Fig. 3 Models showing approach for outdoor area design by ENVI-met version 4.4 program

\section{Results and Discussion}

Table 2 Average PET during period 07:00-18:00 of base case and different design options.

\begin{tabular}{|c|c|c|c|c|c|c|c|}
\hline \multirow{2}{*}{ Time } & \multirow{2}{*}{ Base case } & \multicolumn{2}{|c|}{ Alternative 1 } & \multicolumn{3}{|c|}{ Alternative 2} & \multicolumn{2}{|c|}{ Alternative 3 } \\
\cline { 3 - 8 } & & $\left({ }^{\circ} \mathrm{C}\right)$ & $(\%)$ & $\left({ }^{\circ} \mathrm{C}\right)$ & $(\%)$ & $\left({ }^{\circ} \mathrm{C}\right)$ & $(\%)$ \\
\hline $07: 00$ & 23.96 & 23.95 & -0.05 & 23.95 & -0.05 & 23.95 & -0.05 \\
\hline $08: 00$ & 28.85 & 28.79 & -0.21 & 28.74 & -0.38 & 28.82 & -0.10 \\
\hline $09: 00$ & 37.42 & 37.26 & -0.43 & 37.12 & -0.82 & 37.38 & -0.10 \\
\hline $10: 00$ & 43.29 & 43.06 & -0.53 & 42.86 & -0.99 & 43.23 & -0.14 \\
\hline $11: 00$ & 45.58 & 45.29 & -0.63 & 45.06 & -1.12 & 45.51 & -0.15 \\
\hline $12: 00$ & 46.46 & 46.13 & -0.71 & 45.76 & -1.51 & 46.36 & -0.21 \\
\hline $13: 00$ & 48.36 & 48.26 & -0.20 & 47.80 & -1.15 & 48.32 & -0.08 \\
\hline $14: 00$ & 49.13 & 49.08 & -0.10 & 48.37 & -1.54 & 49.10 & -0.06 \\
\hline $15: 00$ & 49.45 & 49.41 & -0.08 & 48.12 & -2.68 & 49.43 & -0.04 \\
\hline $16: 00$ & 49.31 & 49.27 & -0.08 & 45.82 & -7.62 & 49.30 & -0.03 \\
\hline $17: 00$ & 48.33 & 48.27 & -0.12 & 40.91 & -18.13 & 48.32 & -0.02 \\
\hline $18: 00$ & 36.91 & 36.79 & -0.32 & 36.45 & -1.25 & 36.74 & -0.47 \\
\hline Average & 42.25 & 42.13 & -0.29 & 40.91 & -3.17 & 42.21 & -0.12 \\
\hline
\end{tabular}


The results of the climate data, temperature, and PET from the simulation in the ENVI-met version 4.4 program on the hottest day in Thailand, April 13 during the period 07:00-18:00, measured at 1.40 meters above the ground, are present in Table 2 .

In Table 2, the highest PET value predicted on the site was under Alternative 3 as the wind was blocked by a long line of trees. The most effective option that gives the lowest PET value is Alternative 2, as the trees do not block the wind and give significant shade that blocks the radiation from the sun. The simulation results during the afternoon peak temperature period 13:00-16:00 are shown in Figs. 4-8.

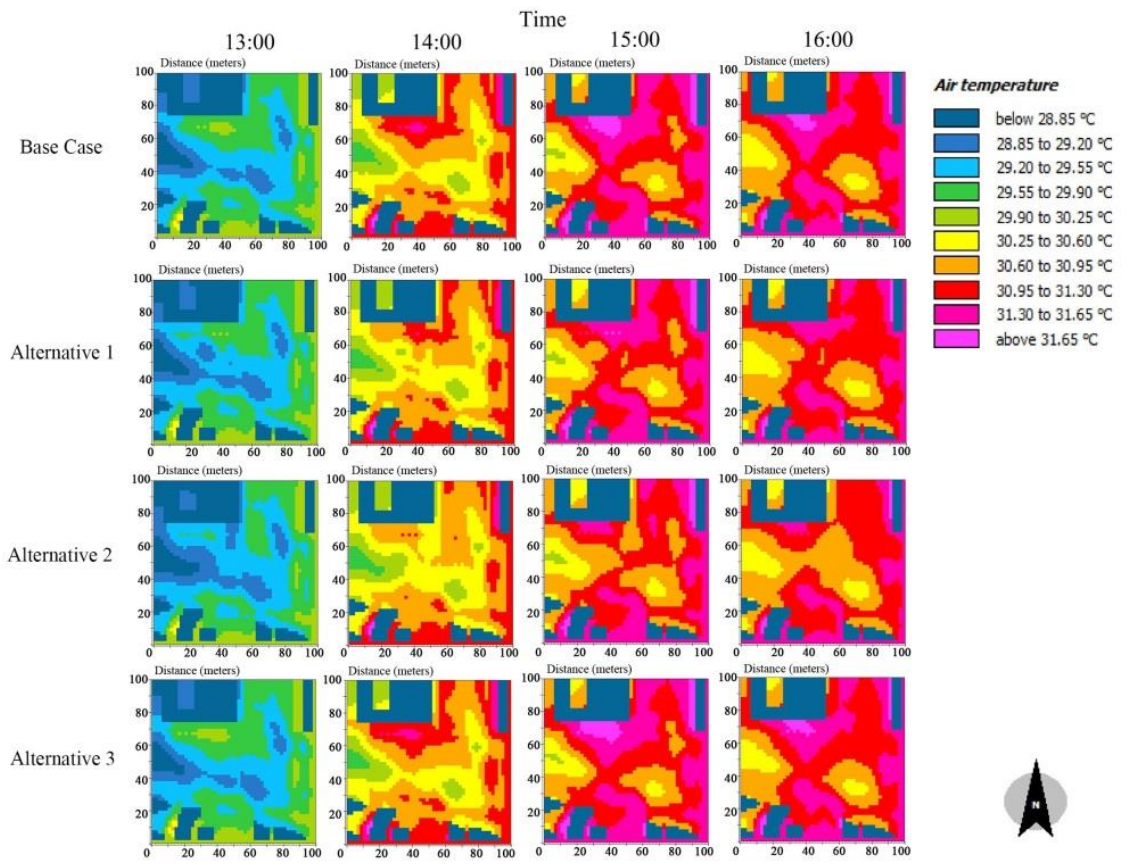

Fig. 4 Air Temperature at $1.4 \mathrm{~m}$ during 13:00-16:00, April 13, 2020

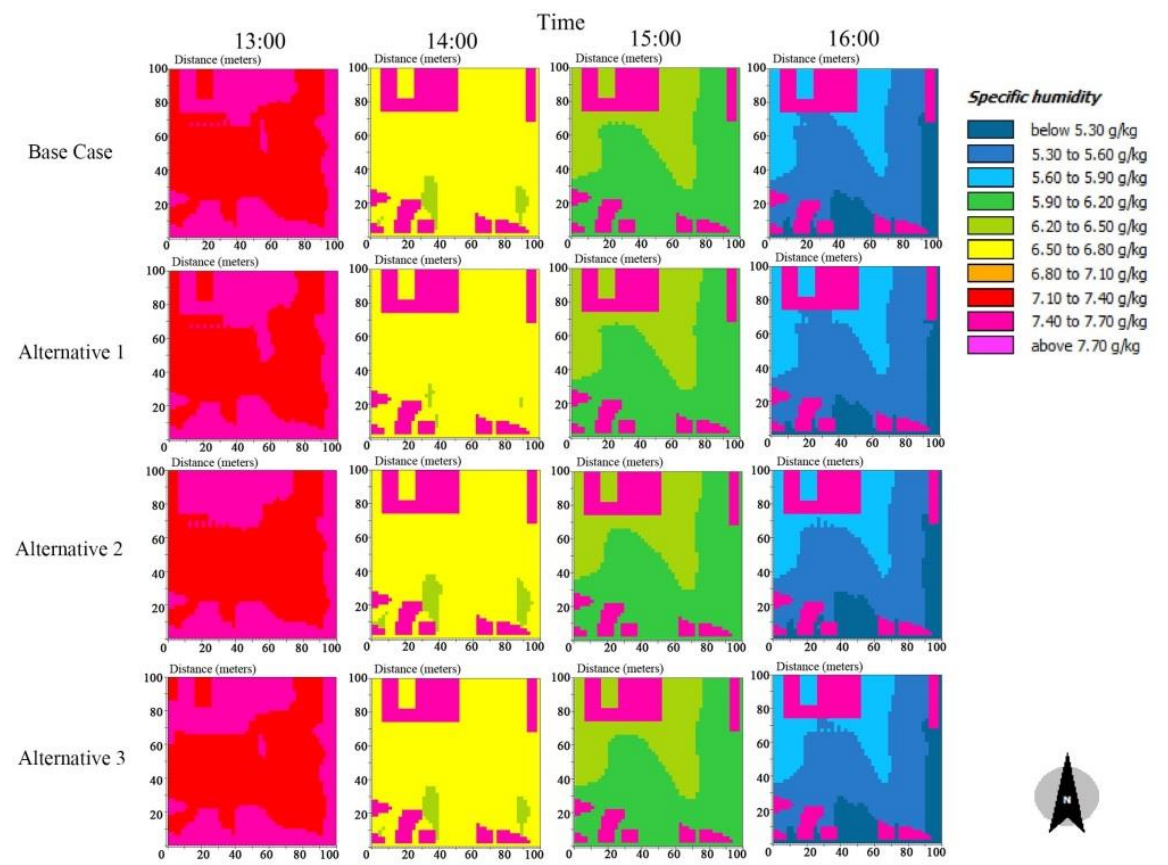

Fig. 5 Specific Humidity at 1.4 m during 13:00-16:00, April 13, 2020

It can be concluded that the hour with the highest PET value for all alternative cases is between 14:00-15:00. According to Srivanit \& Auttarat [14], during this period, the heat accumulated from radiation throughout the day and the rays from the sun causes a high temperature. In addition, the researchers compared the PET values with the base case and the average values obtained in each alternative, and it was found that the difference in the PET during the day compared to the base case 
for Alternative 2 had the greatest difference from the base case at $1.33{ }^{\circ} \mathrm{C}$ and the least difference from the base case of 0.05 degrees as shown in Table 2, especially during the period 16:00-17:00. The average value of the PET for all periods of the base case and Alternatives 1-3 are shown in Table 3.

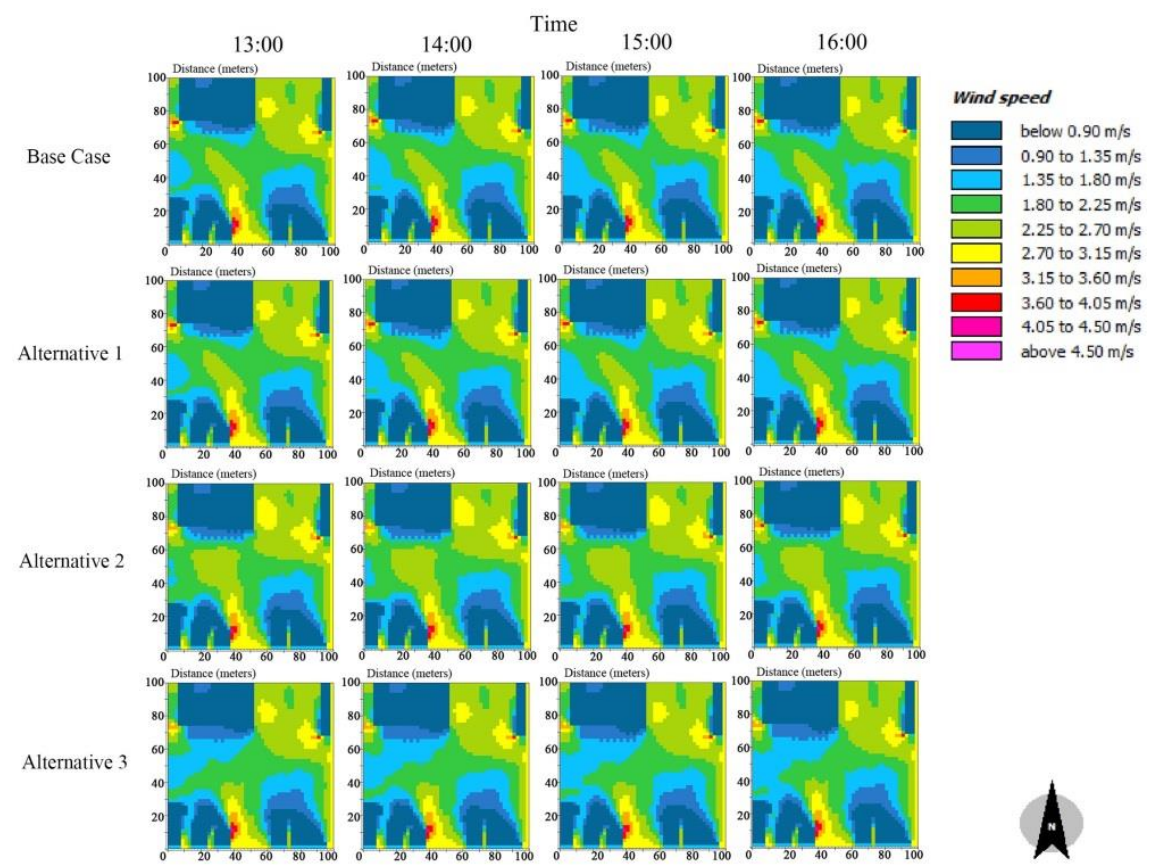

Fig. 6 Wind Speed at 1.4 m during 13:00-16:00, April 13, 2020

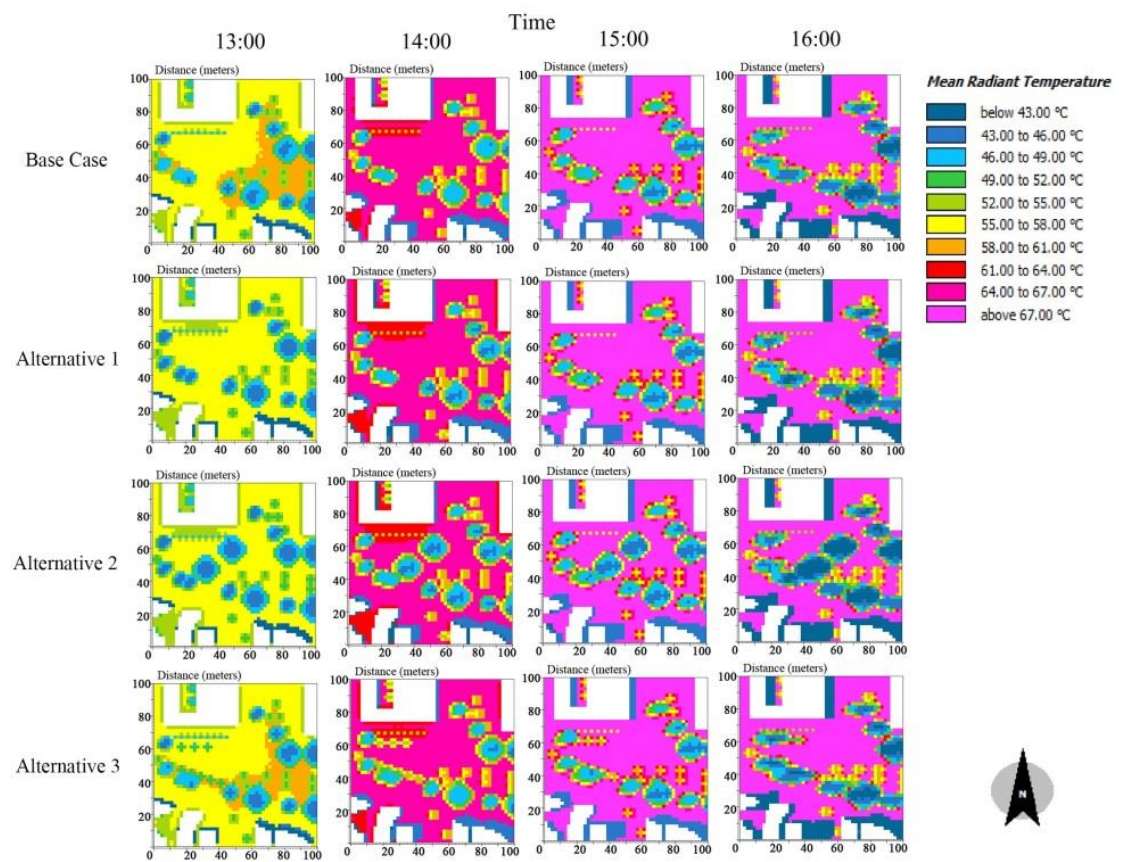

Fig. 7 Mean radian temperature at 1.4 m during 13:00-16:00, April 13, 2020

From Table 3, it can be concluded that Alternative 2 is the best alternative to improve the outdoor thermal comfort for this area, as adding larger trees to the model has a large effect on the PET value. This is consistent with the studies of Gatto et al. [24] and Cheung and Jim [25], which clearly show the benefits of large trees compared to other cases.

Table 3 Average PET values during day

\begin{tabular}{|c|c|c|c|c|}
\hline Time 6.00-18.00 & Base case & Alternative 1 & Alternative 2 & Alternative 3 \\
\hline Average PET & 42.25 & 42.13 & 40.91 & 42.21 \\
\hline Different PET from base case $\left({ }^{\circ} \mathrm{C}\right)$ & & -0.12 & -1.33 & -0.04 \\
\hline Different PET from base case $(\%)$ & & -0.29 & -3.17 & -0.09 \\
\hline
\end{tabular}




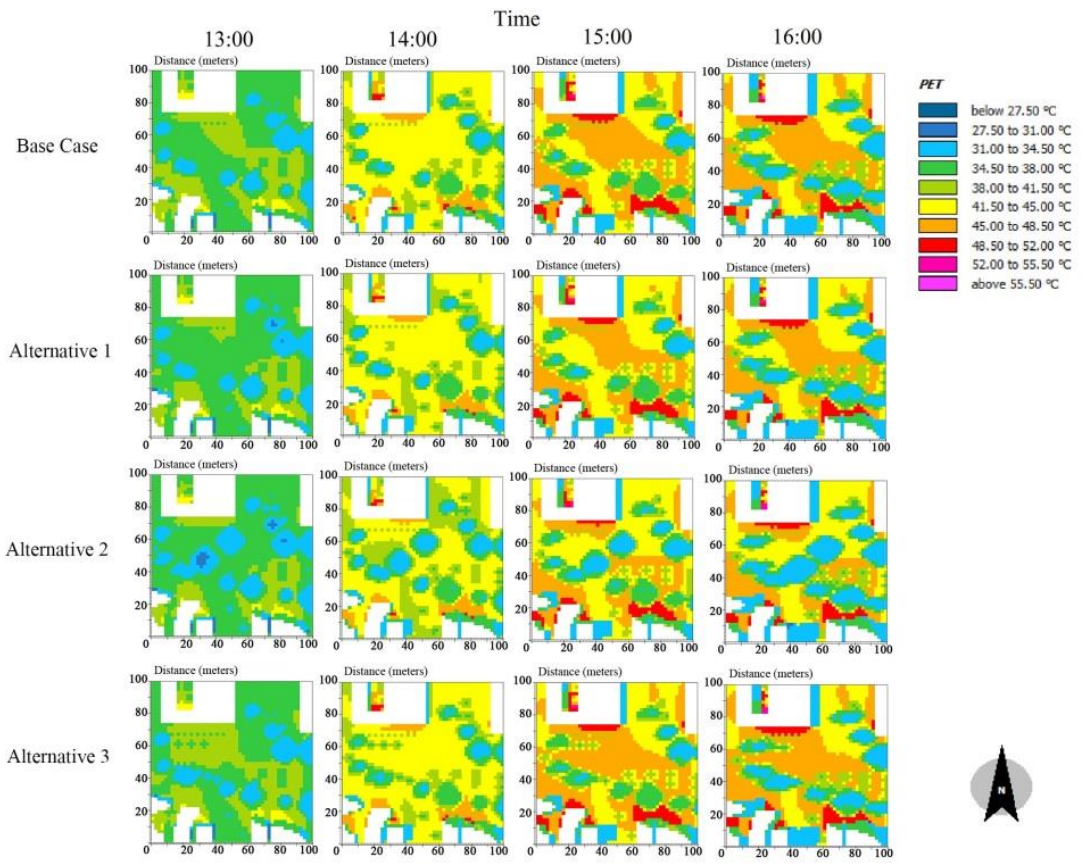

Fig. 8 PET at 1.4 m during 13:00-16:00, April 13, 2020

\section{Conclusions}

This study aims to present an appropriate alternative for improving outdoor public spaces in universities. The study area, named Lan Witsawa Ruamjai, was an open public space, located in the Faculty of Engineering, Chiang Mai University, Chiang Mai, Thailand. It is a space where students can relax or perform activities in the university area. To measure the effects of the design alternatives, PET was the index used to choose the best outdoor thermal comfort design. From the results of the three alternative cases, it was found that the option that uses large trees in the south-west locations of the area had the highest PET reduction, compared with the other cases. The results of the study further support the idea of the benefits of large trees for human habitation in urban areas. This is consistent with previous research.

In addition, to select the most suitable option by using the simulation process in a quantitative technique. This can give a clear understanding to compare and reduce conflicts when choosing a complicated design alternative. It can be used as an example of a design process for new construction and renovation work in other types of construction project to find a balance for sustainable development that can be effective in the future.

\section{Acknowledgement}

This research work was partially supported by the CMU Junior Research Fellowship Program.

\section{Conflicts of Interest}

The authors declare no conflict of interest.

\section{References}

[1] “CMU Smart City Information,” https://enis.cmu.ac.th/audit_analytic/dashboard.php, May 28, 2019.

[2] Z. Huang, B. Cheng, Z. Gou, and F. Zhang, "Outdoor Thermal Comfort and Adaptive Behaviors in a University Campus in China's Hot Summer-Cold Winter Climate Region,” Building and Environment, vol. 165, pp. 1-11, November 2019.

[3] L. Zhao, X. Zhou, L. Li, S. He, and R. Chen, "Study on Outdoor Thermal Comfort on a Campus in a Subtropical Urban Area in Summer," Sustainable Cities and Society, vol. 22, pp. 164-170, February 2016. 
[4] F. Aram, E. Solgi, E. H. Garcia, and A. Mosavi, "Urban Heat Resilience at the Time of Global Warming: Evaluating the Impact of the Urban Parks on Outdoor Thermal Comfort," Environmental Sciences Europe, vol. 32, pp. 1-15, September 2020.

[5] C. M. Peccolo, "The Effect of Thermal Environment on Learning," Department of Health, Education and Welfare Office of Education, University of IOWA, Technical Report, 1962.

[6] P. Höppe, "The Physiological Equivalent Temperature - A Universal Index for the Biometeorological Assessment of the Thermal Environment," International Journal of Biometeorology, vol. 43, no.2, pp. 71-75, October 1999.

[7] Z. Fang, X. Feng, J. Liu, Z. Lin, C. M. Mak, J. Niu et al., "Investigation into the Differences Among Several Outdoor Thermal Comfort Indices Against Field Survey in Subtropics,” Sustainable Cities and Society, vol. 44, pp. 676-690, January 2019.

[8] F. Aram, E. Solgi, S. Baghaee, E. Higueras García, A. Mosavi, and S. S. Band, "How Parks Provide Thermal Comfort Perception in the Metropolitan Cores; A Case Study in Madrid Mediterranean Climatic Zone," Climate Risk Management, vol. 30, pp. 1-14, January 2020.

[9] M. Srivanit and K. Hokao, "Evaluating the Cooling Effects of Greening for Improving the Outdoor Thermal Environment at an Institutional Campus in the Summer," Building and Environment, vol. 66, pp. 158-172, August 2013.

[10] K. Blazejczyk, Y. Epstein, G. Jendritzky, H. Staiger, and B. Tinz, "Comparison of UTCI to Selected Thermal Indices," International Journal of Biometeorology, vol. 56, no. 3, pp. 515-535, May 2012.

[11] E. Johansson, "Influence of Urban Geometry on Outdoor Thermal Comfort in a Hot Dry Climate: A Study in Fez, Morocco," Building and Environment, vol. 41, no. 10, pp. 1326-1338, October 2006.

[12] J. Klaylee, "The Assessment of Physical Design for Outdoor Thermal Comfort: Case Study of Thammasat University (Rangsit Center) (in Thai)," Bachelor, Urban Planning, Thammasat University, Patumthani, http://library.ap.tu.ac.th/searching.php, 2015.

[13] A. Matzarakis, H. Mayer, and M. G. Iziomon, “Applications of a Universal Thermal Index: Physiological Equivalent Temperature," International Journal of Biometeorology, vol. 43, no. 2, pp. 76-84, October 1999.

[14] M. Srivanit and S. Auttarat, "Thermal Comfort Conditions of Urban Spaces in a Hot-Humid Climate of Chiang Mai City, Thailand," The 9th International Conference on Urban Climate, July 2015.

[15] A. Auliciems and S. V. Szokolay, Thermal Comfort, Brisbane: PLEA in Association with Department of Architecture, University of Queensland, 1997.

[16] J. Waewsak, C. Chancham, M. Mani, and Y. Gagnon, "Estimation of Monthly Mean Daily Global Solar Radiation Over Bangkok, Thailand using Artificial Neural Networks,” Energy Procedia, vol. 57, pp. 1160-1168, 2014.

[17] P. Nimnuan and S. Janjai, “An Approach for Estimating Average Daily Global Solar Radiation from Cloud Cover in Thailand," Procedia Engineering, vol. 32, pp. 399-406, 2012.

[18] P. Vangtook and S. Chirarattananon, “An Experimental Investigation of Application of Radiant Cooling in Hot Humid Climate,” Energy and Buildings, vol. 38, no. 4, pp. 273-285, April 2006.

[19] A. Panrare, P. Sohsalam, and T. Tondee, "Constructed Wetland for Sewage Treatment and Thermal Transfer Reduction," Energy Procedia, vol. 79, pp. 567-575, November 2015.

[20] M. Srivanit and K. Hokao, "Effects of Urban Development and Spatial Characteristics on Urban Thermal Environment in Chiang Mai Metropolitan, Thailand," Lowland Technology International, vol. 14, no. 2, pp. 9-22, December 2012.

[21] P. Suropan, D. Rinchumphu, and M. Srivanit, "The Study of Eco-efficiency from Outdoor Thermal Impacts for Hi-end Condominium Project in Central Business District of Bangkok (in Thai)," The National Conference on "Vernacular Creativity Wisdom”, Faculty of Architecture, Chiang Mai University, January 2017, pp. 57-64.

[22] Thai Green Building Institute, Thai's Rating of Energy and Environmental Sustainability for New Construction and Major Renovation, $1^{\text {st }}$ ed. Bangkok: Thai Green Building Institute, 2012.

[23] F. Salata, I. Golasi, R. de Lieto Vollaro, and A. de Lieto Vollaro, "Urban Microclimate and Outdoor Thermal Comfort: A Proper Procedure to Fit ENVI-Met Simulation Outputs to Experimental Data," Sustainable Cities and Society, vol. 26, pp. 318-343, October 2016.

[24] E. Gatto, R. Buccolieri, E. Aarrevaara, F. Ippolito, R. Emmanuel, L. Perronace, and J. L. Santiago, "Impact of Urban Vegetation on Outdoor Thermal Comfort: Comparison between a Mediterranean City (Lecce, Italy) and a Northern European City (Lahti, Finland),” Forests, vol. 11, no. 2, pp. 1-22, February 2020.

[25] P. K. Cheung and C. Y. Jim, "Comparing the Cooling Effects of a Tree and a Concrete Shelter using PET and UTCI," Building and Environment, vol. 130, pp. 49-61, December 2017.

Copyright $\odot$ by the authors. Licensee TAETI, Taiwan. This article is an open access article distributed under the terms and conditions of the Creative Commons Attribution (CC BY-NC) license (https://creativecommons.org/licenses/by-nc/4.0/). 